\title{
FURTHER OBSERVATIONS ON THE USE OF PREGNENOLONE IN RHEUMATOID ARTHRITIS
}

\author{
BY \\ G. NORMAN MYERS and DAVID N. ROSS \\ Regional Medical Research Centre, Royal Bath Hospital, Harrogate
}

In a recent report on the treatment by pregnenolone of a group of ten cases of rheumatoid arthritis (Myers, 1951), two instances of apparent clinical improvement occurred, although there was no appreciable reduction in the erythrocyte sedimentation rate or plasma viscosity readings. Accordingly, it was decided to study the effects of pregnenolone on the serum potassium, sodium, and chlorides, as well as on the urinary $17-$ ketosteroid excretion and leucocyte counts, to find whether any biochemical or hormonal changes parallel the minor clinical response.

\section{Scope of Present Investigation}

Four patients were selected for the investigation. All were females aged between 20 and 41 years, and the duration of the disease varied between 6 and 12 years. They were kept under observation as in-patients of the hospital.

A brief outline of the clinical findings of each case is given. After examination, they were graded according to the system of Steinbrocker and others (1949). Two patients were given $300 \mathrm{mg}$. pregnenolone for 26 days and $100 \mathrm{mg}$. for 8 days; the other two received $300 \mathrm{mg}$. for 27 days and $100 \mathrm{mg}$. for 7 days. The drug was administered by the intramuscular and oral routes. Where the intramuscular route was employed, the pregnenolone was given in the form of a crystule suspension into the upper and outer quadrant of the buttock. The injections often caused pain and a mild inflammation at the site of the injection. In all such cases the volume of the injection was reduced or suspended entirely and the balance of the daily dose of $300 \mathrm{mg}$. given by the sublingual route.

Estimations of the erythrocyte sedimentation rate (Spa Hospitals' Method), plasma viscosity, packed-cell volume, erythrocyte, leucocyte, and eosinophil counts, differential white-cell counts, and haemoglobin estimations, were made at set intervals, before and during the administration of pregnenolone. In addition, estimations were made at intervals throughout the trial of the serum sodium, potassium, and chloride as well as the urinary excretion of 17-ketosteroids, creatinine, and uric acid. All four patients received routine physiotherapy throughout the trial period.

\section{Case Reports}

Case 1. Female, married, aged 38. - In 1944 she travelled to the West Indies, which necessitated a worrying sea trip of 3 weeks' duration via Greenland. About 4 months after her arrival, she developed pain and swelling in the left ankle. One month later the other ankle was similarly affected. She had " electric blanket" treatment, which gave some measure of relief. She returned to England after 7 months and, within 4 days of landing, showed signs of an acute polyarthritis involving the joints of both hands, 
feet, and ankles, and the mandible. She was given a course of gold therapy in addition to physiotherapy. In December, 1944, she became pregnant and the joint condition began to retrogress. In September, 1945, the pregnancy terminated with a stillbirth. Three months later the arthritis became active in the left knee. Since then her condition had deteriorated steadily in spite of five separate courses of gold injections. At time of examination there was evidence of arthritis in both mandibular joints, as well as in the joints of the shoulders, elbows, wrists, hands, ankles, feet, and cervical spine. The onset of the disease was acute, afebrile, and mono-articular. As far back as the grandparents there was no family history of rheumatoid arthritis. Her general health was good immediately before the onset of the arthritis, but she had worried a great deal at the prospect of an ocean voyage in wartime.

Examination.-Thin type of patient, weighing $9 \mathrm{st} .10 \mathrm{lb}$. and taller than average. Both wrist joints enlarged, swollen, and painful, with a markedly restricted range of movements. All metacarpal and interphalangeal joints of both hands show fusiform swelling and restricted, painful movements. Fingers in the extended position. Tenderness over tarsal bones and metatarsophalangeal joints of both feet. Both ankles swollen and painful with limited range of movement. Cervical spine apparently normal. Severe arthritis in both shoulder joints, left elbow, both knees, and both hip joints. No abnormality in respiratory, cardio-vascular, or central nervous systems. Blood pressure $120 / 75 \mathrm{~mm}$. $\mathrm{Hg}$, no evidence of peripheral vascular disturbance. Palmar and plantar surfaces of limbs moist and sweaty. B.M.R. plus 15 per cent.

$X$-Ray Examination.-Fairly advanced arthritis of left hip joint. Acetabulum commencing to bulge. Osteoporosis not marked in the hands and wrists, but considerable destruction of many joints, particularly the proximal interphalangeal joints is seen. Astragulo-scaphoid joints particularly affected in the feet. Some rotation of vertebral bodies of lumbar spine. Lower part of sacro-iliac joints shows chronic inflammatory changes. General osteoporosis and considerable articular erosion in left knee joint. Left elbow joint shows very advanced rheumatoid arthritis with extensive damage; the right elbow appears to be normal. Both shoulder joints show evidence of osteoporosis with considerable erosion of articular surfaces of right joint.

On the eleventh day after the course of pregnenolone had been begun, the patient announced that the degree of joint stiffness had diminished appreciably, but that she still experienced severe pain in the shoulders and elbows at night. This pain was much less severe during the daytime. The knee movements were slightly increased in range and much less painful. Two days later she began to have more pain, especially in the right knee joint. By the twenty-sixth day she felt generally improved, but still had considerable pain in both shoulders and in the right leg, especially the right knee, which was aggravated by movement. Flexion of the knee joints produced crepitus. At this time the sedimentation rate showed an increase. Hip flexion produced severe pain in the groins and lower anterior abdominal muscles. In spite of these pains, she stated that her general condition had undoubtedly improved. During the previous 16 days she had observed that freckles on her skin, which were always very pale and barely discernible, had become darker; they were now much more noticeable and of a deep brownish-black colour. By the 31st day her joints were much less painful and easier to move. Before the course of pregnenolone she usually had $50 \mathrm{gr}$. aspirin a day to ease her pain, but recently she had been able to reduce this to 25 gr. a day, 10 of which she always had at night in order to ensure a " good night's rest".

At the end of the trial period she was sleeping better and was able to turn over more easily in bed and with much less pain. She stated that her joints were better than at any time during the past 4 weeks, and there was no doubt about her being able to get about more easily than before. At the time of examination her menstrual period was 5 days overdue. She was usually very regular and always experienced articular pain during the 2 days before the onset of the menstrual period.

Case 2. Female, married, aged 23.-At age 14, she had experienced transient pains in the muscles and joints of the upper and lower limbs. Soon afterwards there were 
painful swellings in the left elbow, right wrist joint, and both feet. A course of eight gold injections produced an improvement in the ankles and feet. Two additional courses of gold therapy failed to produce any further improvement in her joint condition. During the past 5 years her condition has become progressively worse. She had had two pregnancies and stated that the joint condition improved during each, only to become worse again after delivery. The onset of the disease was acute, afebrile, and polyarticular. In cold weather the hands and feet were unduly cold, the fingers and toes became white, and chilblains often followed. There was nothing of interest in her past history beyond baving twice had pneumonia in childhood; the first time at 1 year, the second at 3 years. She had had two attacks of tonsillitis, the second two years before.

Examination.-Fingers of both hands show swelling of interphalangeal and metacarpophalangeal joints. Right wrist stiff and limited in its movements. Both ankles painful and swollen, with a diminished range of movement. Body weight 10 st.

Respiratory system: poor chest expansion, occasional cough, sometimes expectorates copious amounts of mucus. No abnormal physical signs.

Cardiovascular system: nothing abnormal detected. Blood pressure $120 / 80 \mathrm{~mm}$. Hg. Central nervous system, digestion, and genito-urinary systems all normal. Examination of abdomen revealed nothing of interest. Tonsils small, no evidence of deep infection. B.M.R. plus 10 per cent.

$X$-Ray Examination.-General calcification of the bones good. Marked hypertrophic, arthritic, and erosive changes in right wrist about most of the carpal bones and the articular surface of the radius and the styloid of the ulna. No focal lesions about the joints of the hands, but joint spaces all narrowed. Appearances suggest a late hypertrophic stage of an infective type of arthritis of the wrist joint. Bones of the feet show a generalized bone rarefaction and narrowing of joint spaces. No focal erosive changes. Left elbow appears to be ankylosed. Lateral view of the right elbow shows narrowing of joint spaces, but no erosive bone changes. Left knee shows a diminution of the semilunat cartilage spaces.

After having had pregnenolone for 11 days, she stated that she felt generally improved, and that the arms and neck were less painful and stiff than before. The pain returned on the eighteenth day. The joint movements, however, remained free and she had a good range,especially in the right knee, which could be fully extended, though the movement was somewhat guarded and slow. Her general health appeared better. The pain subsided over the next few days. On the twenty-sixth day she stated that she was greatly improved in every way. The limb muscles were in excellent condition, while the joint movements were less painful and freer than at any time since she had been admitted to hospital. Most of the pain was in the right knee. By the thirty-second day she was walking better, in spite of the painful right knee. She could negotiate steps and was not so easily tired as before. Her general health had greatly improved.

Case 3. Female, unmarried, aged 20.-At age 12, she had received a severe blow on the left knee which prevented her from walking for a few weeks. Pain and swelling of both knees quickly followed. The condition soon involved the feet, hands, wrists, and elbows, and, later, the hip and shoulder joints. Gold therapy had little effect upon the joint condition. During the past five years she had had a number of natural remission phases which, however, were only partial. These were always followed by relapses and her joints have steadily deteriorated to their present state. In all, she had had four courses of gold therapy without success. The onset of the arthritis was acute, afebrile, and polyarticular. There was no history of rheumatism in her family as far back as the grandparents. There was evidence of a disturbed peripheral circulation, shown by the coldness of her fingers and toes, which readily became blue, especially in cold weather.

Examination.-Pale complexion and anxious expression, thin and underweight. Patient walks with a marked limp and some pain. Fusiform swellings of metacarpo-phalangeal joints of both hands. Similar swellings present over proximal phalangeal joints. Both wrists show a 
flexion deformity with limited extension of the elbows. Knees and ankles, as well as metatarsophalangeal joints of both feet, swollen and tender. Hips painful on movement, with gross limitation of movement, abduction $15^{\circ}$, flexion $20^{\circ}$. Limited flexion of spine. Examination of the respiratory, central nervous, and cardiovascular systems showed nothing of interest beyond a blood pressure of 140/90 mm. Hg. Digestion good, but appetite poor. Tip of spleen just palpable. Nothing abnormal in the urinary system beyond an occasional urgency of micturition. B.M.R. minus 2 per cent.

$X$-Ray Examination.-Carpal joints mainly involved, with erosion of left radio-carpal joint. Advanced arthritis of left elbow joint. Knee joints show generalized osteoporosis. Articular surfaces of right knee show evidence of arthritis. Acromio-clavicular arthritis on right side. Left shoulder shows osteoporosis of humeral head. Hip joints show advanced arthritis of atrophic type.

After four days of pregnenolone administration, the patient stated that her joints were not so stiff as before, but complained of dryness in the mouth during the greater part of the day. Two days later she showed signs of an intercostal fibrositis on the right side. On the eleventh day she stated that she did not feel so well. Her appetite had been deteriorating slowly since the injections were started. Because of this, the frequency of the injections was reduced to alternate days, whilst the balance of the daily dose of $300 \mathrm{mg}$. was given in the form of sublingual tablets. At this time she experienced an increasing tenderness in her feet and ankles. The injections were stopped and the whole of the $300 \mathrm{mg}$. pregnenolone administered by the sublingual route. During the next 7 days the pains became steadily worse. She believed that the pain commenced soon after the intramuscular injections were reduced and got worse after they were stopped. The pain was not so intense by the twenty-sixth day, but she still experienced a fair amount of pain when the joints were moved during examination. At this time she was walking very badly. The pain was mainly located in the dorsum of both feet, both knees, and groins, and the left shoulder. At the end of the trial her condition had not altered materially.

Case 4. Female, unmarried, aged 41.-She was well-nourished and weighed 10 st. $2 \mathrm{lb}$. In September, 1943, she experienced pain and swelling in both feet and hands. Later the knee joints became involved. A course of twelve gold injections appeared to improve her condition for a few months, when she relapsed to her former condition. In April, 1950 , the knees became very swollen and she had to go to bed for 6 weeks. When she got up from her bed, she was unable to walk without crutches and she had been obliged to continue with these ever since.

Past History.- - In 1932 she was found to be a diabetic and had been under treatment for the condition continuously since then. She stated that immediately before the onset of her arthritic condition, she experienced a severe mental shock over the death of a very close friend. About the same time she had an attack of chicken-pox. The onset of the arthritis was acute, febrile, and polyarticular, with no evidence of rheumatoid arthritis in her family history, or any peripheral vascular disturbances beyond persistently cold feet.

Examination.-Fusiform swellings over metacarpo-phalangeal and proximal interphalangeal joints of both hands. Both ankles and left knee swollen and tender on pressure, with limited movements. Hip joints and spine appear normal. Nothing abnormal in respiratory, cardiovascular, or central nervous systems. Blood pressure raised to $160 / 95 \mathrm{~mm}$. Hg. Urine contains protein and sugar in small amounts. Abdominal examination revealed nothing abnormal. B.M.R. plus 18 per cent. Serum colloidal gold reaction positive (3).

$X$-Ray Examination.-Left knee shows advanced degree of arthritis of infective or atrophic type, with much articular erosion, including the patellar surface. Right knee shows no abnormality. Osteoporosis in bones of both ankles, particularly the left. Tarsal bones show roughening of the surfaces in addition to slight osteoporosis.

This patient felt generally worse during the first 13 days of pregnenolone administration. Her chief complaint was of increased stiffness in all her joints and a feeling of being " run-down". By the twentieth day she became mentally depressed and experienced 
increased pain in her feet and knee joints. Six days later she was still complaining of pain in her left knee, which was aggravated by weight-bearing. The feet were cold and the ankles ached when she retired to bed. There was marked oedema of both ankles, the left being worse than the right. Her general health, however, appeared to have improved. The mental depression had disappeared by the twenty-ninth day, but she still complained of pain in the left knee, especially at night. This patient showed no signs of any joint improvement during the period of the trial.

The cases were graded according to the Steinbrocker classification (1949). In no case was the functional capacity altered by pregnenolone, although some minor improvement was shown in three cases which were assessed as a Grade 3 response. No response was recorded in the fourth case.

\section{Dosage of Pregnenolone, Erythrocyte Sedimentation Rate, and Plasma Viscosity Rates}

The mode of administration of the daily dose of pregnenolone over the trial period of 34 days, and the reaction, calls for description.

Dosage.-During the first 26 or 27 days, the individual daily dose was $300 \mathrm{mg}$, but towards the end of this period, all the subjects complained of increasing stiffness in their joints. No definite cause could be assigned to this, but it was considered possible that the condition might be due to the pregnenolone. In view of this possibility, the daily dose was reduced to $100 \mathrm{mg}$. during the remaining 7 or 8 days of the trial.

Erythrocyte Sedimentation Rate.-In three cases there was a decrease in the rate after pregnenolone. Two of these were accompanied by a slight reduction in viscosity rate, while in the third case the viscosity rate was slightly raised over the same period. The fourth case showed a small increase in the erythrocyte sedimentation rate, whilst the viscosity rate was reduced slightly.

Other Findings.-No significant changes in serum sodium, potassium, or chlorides were observed throughout the trial. Erythrocyte counts, haemoglobin per cent., colour index, and packed-cell volume per cent. showed no change. Urinary 17-ketosteroid excretion was not influenced by pregnenolone.

Leucocyte Counts.-These are shown in Fig. 1. Cases 2 and 4 show a close similarity in the course followed. In each case there is a marked reduction in the number of circulating leucocytes, after the administration of pregnenolone. The results in Cases 1 and 3 are not so clear-cut; the end result shows only a small reduction in the number of leucocytes. If the final leucocyte count in Case 3 were omitted, the response would show little or no change.

Eosinophil Counts.- These are shown in Fig. 2. It is obvious that pregnenolone has no influence on the number of circulating eosinophil cells.

Estimations of Urinary Creatinine and Uric Acid.-These estimations, as well as the creatinine/uric acid ratio, are set out in the Table (overleaf). The initial determinations $(24 / 1 / 51)$ were made on the day before the administration of pregnenolone was begun. In Cases 1 and 2 the creatinine excretion figures show an increase on the 


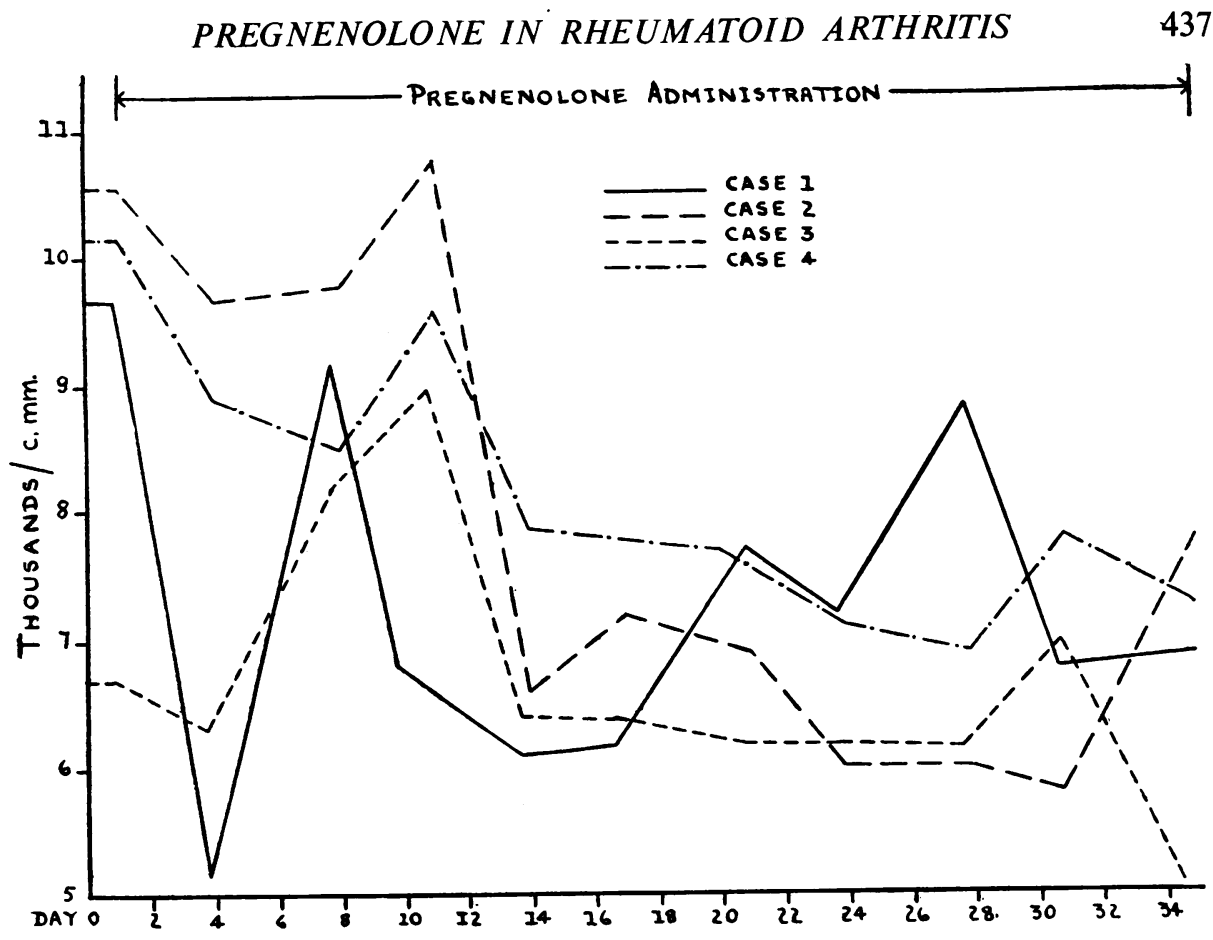

Fig. 1.-Leucocyte counts.

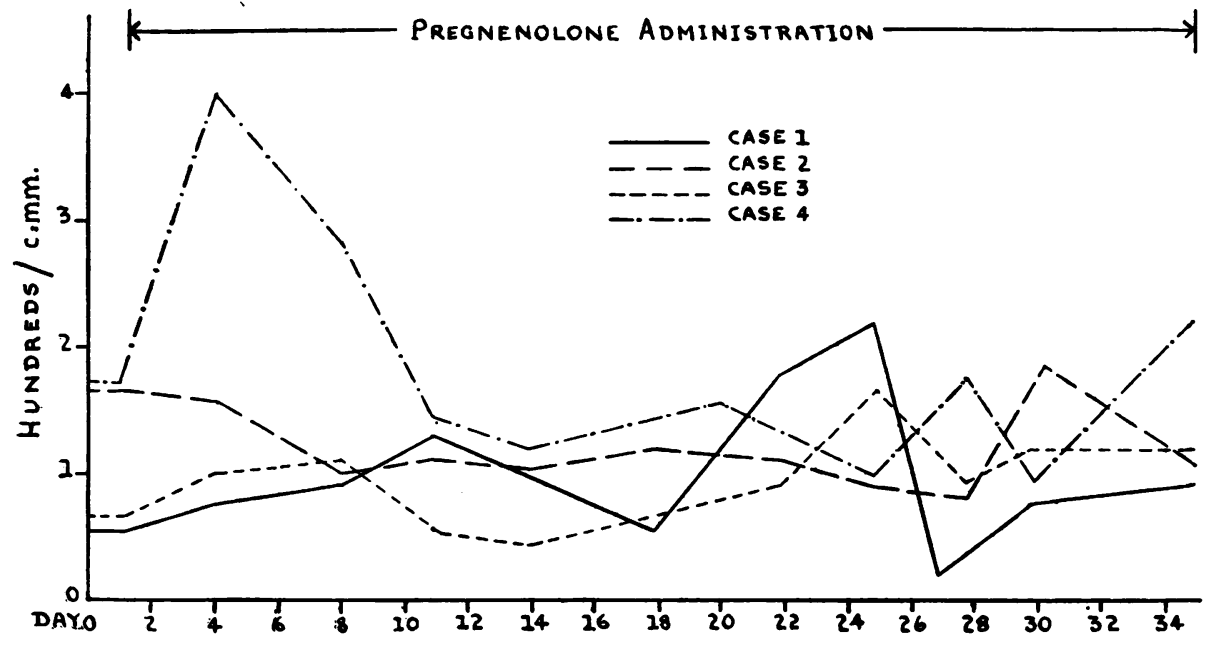

FIG. 2.-Eosinophil counts.

23rd day of pregnenolone administration (17/2/51). A similar increase was not observed in Cases 3 and 4, and it is doubtful whether this is of any significance.

\section{Discussion}

The clinical results of this investigation show that of the four patients, two (Cases 3 and 4) derived no benefit whatsoever from the administration of $300 \mathrm{mg}$. 
TABLE

ESTIMATION OF URIC ACID, CREATININE, AND

URIC ACID/CREATININE RATIO

\begin{tabular}{|c|c|c|c|c|}
\hline Case No. & Date & Uric Acid & Creatinine & U/C Ratio \\
\hline 1 & $\begin{array}{l}24 / 1 / 51 \\
11 / 2 / 51 \\
13 / 2 / 51 \\
17 / 2 / 51 \\
21 / 2 / 51 \\
24 / 2 / 51\end{array}$ & $\begin{array}{l}500 \\
745 \\
725 \\
500 \\
650 \\
645\end{array}$ & $\begin{array}{r}885 \\
990 \\
875 \\
1,100 \\
1,190 \\
930\end{array}$ & $\begin{array}{l}0.56 \\
0.75 \\
0.83 \\
0.45 \\
0.55 \\
0.69\end{array}$ \\
\hline 2 & $\begin{array}{l}24 / 1 / 51 \\
11 / 2 / 51 \\
13 / 2 / 51 \\
17 / 2 / 51 \\
21 / 2 / 51 \\
24 / 2 / 51\end{array}$ & $\begin{array}{l}390 \\
695 \\
815 \\
485 \\
480 \\
580\end{array}$ & $\begin{array}{r}510 \\
615 \\
700 \\
1,006 \\
715 \\
1,000\end{array}$ & $\begin{array}{l}076 \\
1 \cdot 1 \\
1 \cdot 16 \\
0448 \\
0 \cdot 67 \\
0 \cdot 58\end{array}$ \\
\hline 3 & $\begin{array}{l}11 / 2 / 51 \\
13 / 2 / 51 \\
17 / 2 / 51 \\
21 / 2 / 51 \\
24 / 2 / 51\end{array}$ & $\begin{array}{l}355 \\
540 \\
665 \\
490 \\
590\end{array}$ & $\begin{array}{l}430 \\
605 \\
660 \\
605 \\
705\end{array}$ & $\begin{array}{l}0 \cdot 82 \\
0 \cdot 89 \\
1 \cdot 0 \\
0 \cdot 81 \\
0 \cdot 83\end{array}$ \\
\hline 4 & $\begin{array}{l}24 / 1 / 51 \\
11 / 2 / 51 \\
13 / 2 / 51 \\
17 / 2 / 51 \\
21 / 2 / 51 \\
24 / 2 / 51\end{array}$ & $\begin{array}{r}530 \\
645 \\
580 \\
600 \\
645 \\
1,120\end{array}$ & $\begin{array}{r}855 \\
585 \\
950 \\
920 \\
825 \\
1,260\end{array}$ & $\begin{array}{l}0 \cdot 62 \\
1 \cdot 1 \\
0.61 \\
0.65 \\
0 \cdot 78 \\
0 \cdot 88\end{array}$ \\
\hline
\end{tabular}

pregnenolone daily over a period of 34 days. In neither case was there any diminution of pain or improvement in joint movements. One (Case 3) experienced a marked deterioration of appetite, whilst the other (Case 4) showed signs of mental depression from the 20th to the 29th day of the trial period.

Case 1 experienced some diminution of pain, needed fewer aspirin tablets, and was sleeping better by the 30th day. The improventent in joint movement was extremely small, but the patient was much happier and more contented than before.

Case 2 stated that she was greatly improved. Joint pain and stiffness were reduced, and walking improved so that she was better able to negotiate steps without undue fatigue.

In spite of these divergent results, most of the laboratory estimations showed little change during the period of pregnenolone administration. Of the two patients who derived no benefit from pregnenolone, one (Case 3) showed a slight reduction in the erythrocyte sedimentation rate, with no change in plasma viscosity, and the other (Case 4) showed a small increase in the erythrocyte sedimentation rate, accompanied by a correspondingly small reduction in plasma viscosity. In the only patient who experienced a marked improvement (Case 2) the erythrocyte sedimentation rate fell dramatically from 31 to 9 per cent., but the alteration in the plasma viscosity was negligible. Case 1 showed only a minor degree of improvement, and the erythrocyte sedimentation rate fell from 35 to 29 per cent., while the plasma viscosity was reduced from $21 \cdot 8$ to $20 \cdot 6$. 
The leucocyte counts show that the two patients not improved by pregnenolone both showed a definite reduction in circulating leucocytes and that the course followed by each was approximately the same. On the other hand, Cases 1 and 2 showed some clinical improvement, and also show a very slight decrease in leucocytes. It is difficult to interpret these results, because if pregnenolone in any way resembled cortisone, especially in its effects on the tissues, one might have expected the greater reduction in the total leucocyte counts to have been evident in the two cases which showed clinical improvement. Thus one cannot believe that these two compounds have any similarity in their mode of physiological action.

Pregnenolone does not appear to influence serum potassium, sodium, or chlorides. Nor does it affect the creatinine/uric acid ratio or the urinary 17-ketosteroids.

Pigmentation of both skin and nails is mentioned by Thorn and others (1950) as occasionally complicating both cortisone and ACTH administration for long periods. They suggest that this may be related to interference with sulph-hydryl systems in the tissues concerned, allowing melanin deposition. In the present investigation, one patient (Case 1) showed a deepening in colour of the skin freckles, from a faint, almost imperceptible yellowish colour, to a deep brownish-black hue, almost like dark mahogany. According to the patient's own statements, this colour change, which is usually associated with melanin deposition, had never occurred to her before, not even when she lived in the bright sunshine of the West Indies. Whether there is any relationship between the pigmentary changes in the skin, described by Thorn and his co-workers, and the changes seen in our patient, it is difficult to say. In our case the deep pigmentation did not assume a general distribution over the skin surface, but only occurred where freckles had previously existed.

The results do not support the belief that pregnenolone exercises any beneficial action in rheumatoid arthritis.

\section{Summary}

(1) Four female patients suffering from rheumatoid arthritis were given a daily dose of $300 \mathrm{mg}$. pregnenolone by the intramuscular and sublingual routes for a period of 34 days.

(2) Two cases showed no improvement whatsoever; one showed a very minor clinical improvement; the fourth showed a more marked clinical improvement.

(3) Pregnenolone did not influence the serum content of sodium, potassium, or chlorides, nor had it any effect upon the creatinine/uric acid ratio.

(4) The leucocyte response to pregnenolone was not consistent. The two cases which showed no clinical improvement showed a reduction in the circulating leucocytes; the reduction in the other two cases was so small as to be negligible.

'We should like to thank Messrs. Ciba Ltd., for the supply of pregnenolone, and Dr. Gerard Lorriman for his help in many ways, and we are indebted to Mr. Steel of the Royal Bath Hospital for the blood counts, and Mr. Moffett for the chemical estimations. 


\section{REFERENCES}

Myers, G. N. (1951). Annals of the Rheumatic Diseases, 10, 32.

Steinbrocker, O. M., Traeger, C. H., and Batterman, R. C. (1949). J. Amer. med. Ass., $140,659$.

Thorn, G. W., Forsham, P. H., Frawley, T. F., Hill, S. R., Roche, M., Staehelin, D., and Wilson, D. L. (1950). New Engl. J. Med., 242, 783, 824, 865.

\section{Nouvelles observations sur l'emploi de la pregnenolone dans le traitement de l'arthrite rhumatismale}

\section{RÉSUMÉ}

(1) Quatre malades atteints d'arthrite rhumatismale reçurent pendant une période de 34 jours la dose quotidienne de $300 \mathrm{mg}$. de pregnénolone par voie intramusculaire ou sublinguale.

(2) On n'observa aucune amélioration dans deux cas; il ent une très faible amélioration clinique dans un cas et ure, plus prononcée, dans le quatrième.

(3) La pregnénolone ne modifia pas le taux sérique du sodium, du potassium ni des chlorures; elle n'exerça, non plus, aucun effet sur le quotient créatinine/acide urique.

(4) La réaction leucocytaire à la pregnénolone fut paradoxale: il eut une leucopénie dans les deux cas non améliorés; dans les deux autres cas la leucopénie fut si peu marquée qu'on peut la considérer comme négligeable.

\section{Observaciones ulteriores sobre el uso de la pregnenolone en el tratamiento de la artritis reumatoide}

\section{SUMARIO}

(1) Cuatro enfermos con artritis reumatoide recibieron durante un período de 34 días la dosis diaria de $300 \mathrm{mg}$. de pregnenolone por vía intramuscular o perlingual.

(2) En dos casos no se vió mejoría alguna; hubo poca mejoría clínica en otro y más pronunciada en el cuarto caso.

(3) La pregnenolone no cambió la cifra del sodio, del potasio o de los cloruros en el suero; no tuvo, tampoco, efecto alguno sobre el cociente creatinina/ácido úrico.

(4) La reacción Jeucocitaria a la pregnenolone fué paradójica: leucopenia evidente en los dos casos sin mejoría e insignificante en los demás. 